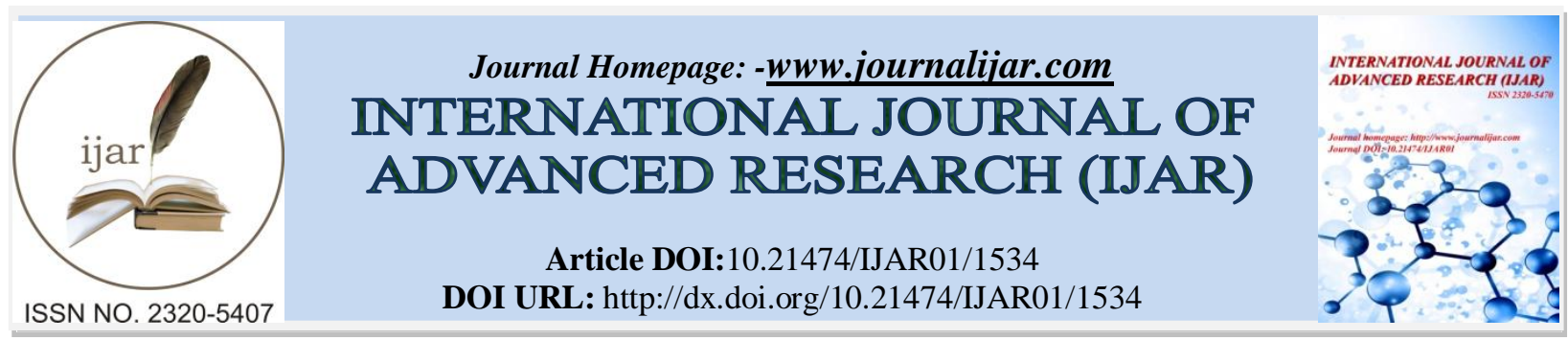

RESEARCH ARTICLE

\title{
THE LINGUISTIC ATLAS OF THE EAST OF GUILAN AND THE NATIONAL PROJECT OF THE DIALECTOLOGY OF IRAN
}

\section{Maryam Mahlouji Afshar ${ }^{1}$ and Iran Kalbassi ${ }^{2}$}

1. M.A in General linguistics, Islamic Azad University, CentralTehran Branch, Tehran, Iran.

2. PH.D, Professor of Islamic Azad University, CentralTehran Branch and Institute for Humanities and Cultural Studies, Tehran,Iran.

\section{Manuscript Info}

\section{Manuscript History}

Received: 13 July 2016

Final Accepted: 19 August 2016

Published: September 2016

\section{Key words:-}

language, dialect, accent, linguistic atlas, language variety, standard language

\section{Abstract}

Thesignificance of theresearch on Iranian dialects is clear for everyone. According to this goal, "The National Project oftheDialectology of Iran" has been started in 1999. Up to now in relatedto this project, 18theses in Iranian universities, especially in Islamic Azad University Central Tehran Branch,has been fulfilledon the dialects of some provinces of Iran.This article is based on this project and it is about the dialects of the Eastof Guilan province. The purpose of this research is to find the similarities and differences of the dialect or accent in 20 villages in this region in terms of phonetic, grammatical and lexical analysis that will be carried out by questionnaire and finally provided as a linguistic atlas.

Copy Right, IJAR, 2016,. All rights reserved.

\section{Introduction:-}

Identity and authenticity of every culture and nation are rooted in its language. In other words, native language of every nation is the authenticand valuable treasure of the antiquity and history of that nation. Therefore,every effort on preserving and saving thisprecious wealth is admirable and important. Iran is a land with many language diversities, dialects and accents; thus in the linguistic studies, the study of(New)Iranian dialectsas a branch of the Old Iranian language, and Iranian languages as a branch of Indo-Iranian languages, is very important. Extinction of each language and its dialect and accent will lead to decline and extinction of a culture and civilization, that it would be irremediable. So put theindividual and collective scientific efforts into the recording of thelanguages and dialects of different ethnic groups can pave the way for studying and doing a research on the humanitiessuch as sociology, psychology, anthropology,etc. In this global effort, Persian language with thousands of years of history and richness can be a great contribution to protect thecultural andsocial history of the world.In this regard, preparing a linguistic atlas for each language and country is very important and useful in collecting different dialects of that country in aform of a linguistic encyclopedia. Providing the linguistic atlas of the Eastof Guilan is a scientific research in achieving the efforts of the great linguistics masters of our country - Dr. YadollahSamareh and Dr. Iran Kalbassi and other researchers who have taken steps in realization of "The National Project of the Dialectology of Iran".Other researchers in different majors and even non-Persian language researchers could use the result of that and it will be useful in promoting Persian language structure, theancient human language, whether in education or making new words.

Corresponding Author:-Maryam MahloujiAfshar.

Address:-m_mahlouji_afshar@yahoo.com 


\section{Review of literature:-}

The researchers of the dialects of theSouthern coast of the Caspian Sea, including theIranian and non-Iranian researcherswill be cited briefly:

* Gmelin is the biological and ethnological scientist that we owe him for the first awareness of Guilaki dialect in the second half of the eighteenth century, published the book "ReiseDurchRusslandZurUntersuchung Der DreyNaturreiche" in Saint Petersburg in 1775. He mentioned some Guilaki words in the third part of his book.

* Chodzko, Polish researcher, published the book "Specimens of Popular Poetry of Persia"in London in 1842 about the Northern parts of Iran and Guilaki dialect.

* Christensen, the professor of Persian Philology in the University of Copenhagen, a researcher who, in addition to his contributionon some Old Iranian languages, has many works inIranian literature and culture also Iranian dialects. He wrote the description of the grammatical structure of Guilaki dialect based on Guilaki dialect of Rasht in the book "DialecteGuiläkî De Recht"that it was translated by Khomamizadeh in 1995.

* Geiger, German linguist,wrotean article entitled "Die KaspischenDialekte" in his book "Grundriss Der IranischenPhilologie"in 1896. He consideredall the knowledge that scholars collected about the phonetics and grammatical structure of Guilaki dialectuntil the end of the nineteenth century.

* Schmit, the contemporary professor, presented a book entitled "Compendium LinguarumIranicarum" in 1989, has edited and published an overview of past and present Iranian languages and it is the findings of many years' efforts of seventeen prominent scientists of linguistics. In the section of theWestern Iranian dialects, the dialects of the coast of Caspian Sea in terms of phonetics, morphology, syntax and lexicon are carefully studied.Baghbidi has translated it into Persian in 2003.

* Sotoudeh is one of the Iranian researchers who by publishing articles and books as "GuilakiDictionary" in 1953 had a great contribution in identifying the dialects of thisregion.

* PayandehLangaroudi has published the book entitled "A Dictionary ofGuilaki and Deilami Proverbs and Idioms" which is the part of the folklore of the regionin 1968. In addition, he wrote the book "A Dictionary of Guilakiand Deilami"that is a set of words and phrases from all regions of Guilan in 1987 and the book "The Religions and Believes of Guilaki and Deilami" in 1998.

* Sartippour has published the book entitled "Grammatical Characteristics and A Dictionary of Guilaki Terms" in 1990,that analyses the phonetics, phonology and morphology of Guilaki in Rasht.

* Kalbassi is one of the researchers that has donemany researches on the subject thatsome of her researches are the booksentitled"The Dialect of Kalardasht (Roudbarak)" in 1997 and "A Descriptive Dictionary of Linguistic Varieties in Iran" in 2009.

* BakhshzadMahmoodi in 2011 in the book "Guilaki Grammar" has explained in detail,the morphology,syntax and punctuation of Guilaki simply.

In addition, the various theses have done in this field are as follows:

Shokouhi, 1999, "The Verb Phrase Structure in the Dialect of Guilakiin Langaroud". Abdollahzadeh, 2003, "The Phonetic and Dialect System in AstanehAshrafieh". AzariHamidian, 2003, "The National Project of the Dialectology of Iran, No. 2 (40 Villages in Mazandaran and Guilan)". AbdollahtabarGhasemabadi, 2011, "The National Project of the Dialectology of Iran, No. 7 (30 Villages in the East of Guilan)".

Moreover, some articles related to this study are as follows:

Basirat and Famian, 2011, "Towards Mapping out A Guilaki Dialect Atlas". Mir HashemiJorshari, 2012, "The Verbal Prefix /bv-/ in the Simple Past Tense of Guilaki from Creation to Declension". Shabani, 2014, "The Description and Analysis of the Discontinuous Focus in Guilaki Language (Eshkevarat Dialect)".

\section{Purpose of the Study:-}

The presence of Guilak nationandthe dialects of Guilan, whether in the East orin the West, cause the area to be linguistically important forthe numbers ofspeakers and the variety of different dialects and accents in a similar geographical situation.Providingthelinguistic atlas that shows and presents various dialects of this region, can be an important step for facilitating social, historical, indigenous and cultural studies.Moreover, it is possible for linguists and who are interested in the culture to have access to acomprehensive source on the study of a dialect with variousaccents, which are different in phonetics, morphology, syntax and lexicon with the standard Persian.

\section{Methodology:-}

This study was the library and field study, and the data collection was based on a questionnaire consisting of 100 words, by sampling of 20 villages in the East of Guilan province from AstanehAshrafieh to the end of the Eastern 
region of Guilan, Chaboksar. The data collected from each village analyses in descriptive-analytic method and the findings added tothe table, which is related to each word.

After comparing the differences and similarities in phonetics, morphology, syntaxand lexiconof each word with the standard Persian, the result was marked with signs on the map of the region. Finally, the linguistic atlas has been prepared.

To achieve the authentic accents, the middle-aged speakers who spent most of their life in that region have participated in the research,and villages with more phonetic differences in accent have been considered.

\section{Languagepoints analysis:-}

The findings of this study are divided into phonetic, morphological, syntactic and lexicaldata. Some examples provided in each section.

Phonetic analysis on vowels are as follows: 1.Vowel replacement; 2.Vowel elision; 3.Vowel insertion; 4.Vowel length; 5.Vowel elision and vowel length simultaneously with consonant elision.

\section{Vowel replacement :-}

Sometimes the vowel [ə]in Guilaki is the equivalent to the vowel [â] in the standard Persian: fard모

"Tomorrow"

fardâ

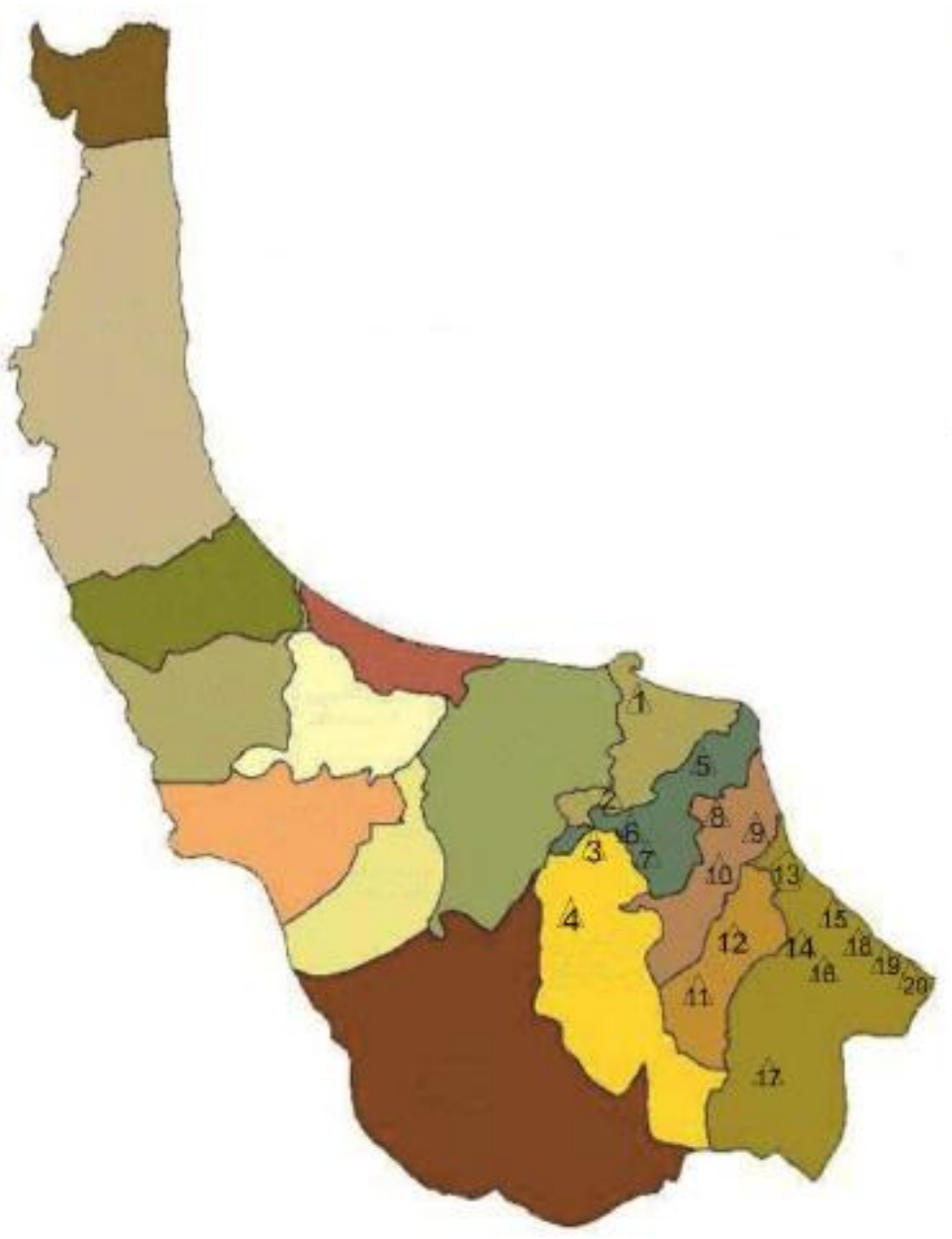

Figure 1 . The atlas of

"Tomorrow"

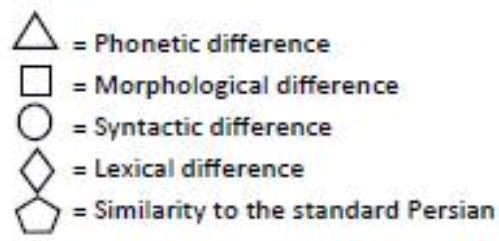


Vowel length:-

baro:n

bârân

"Rain"

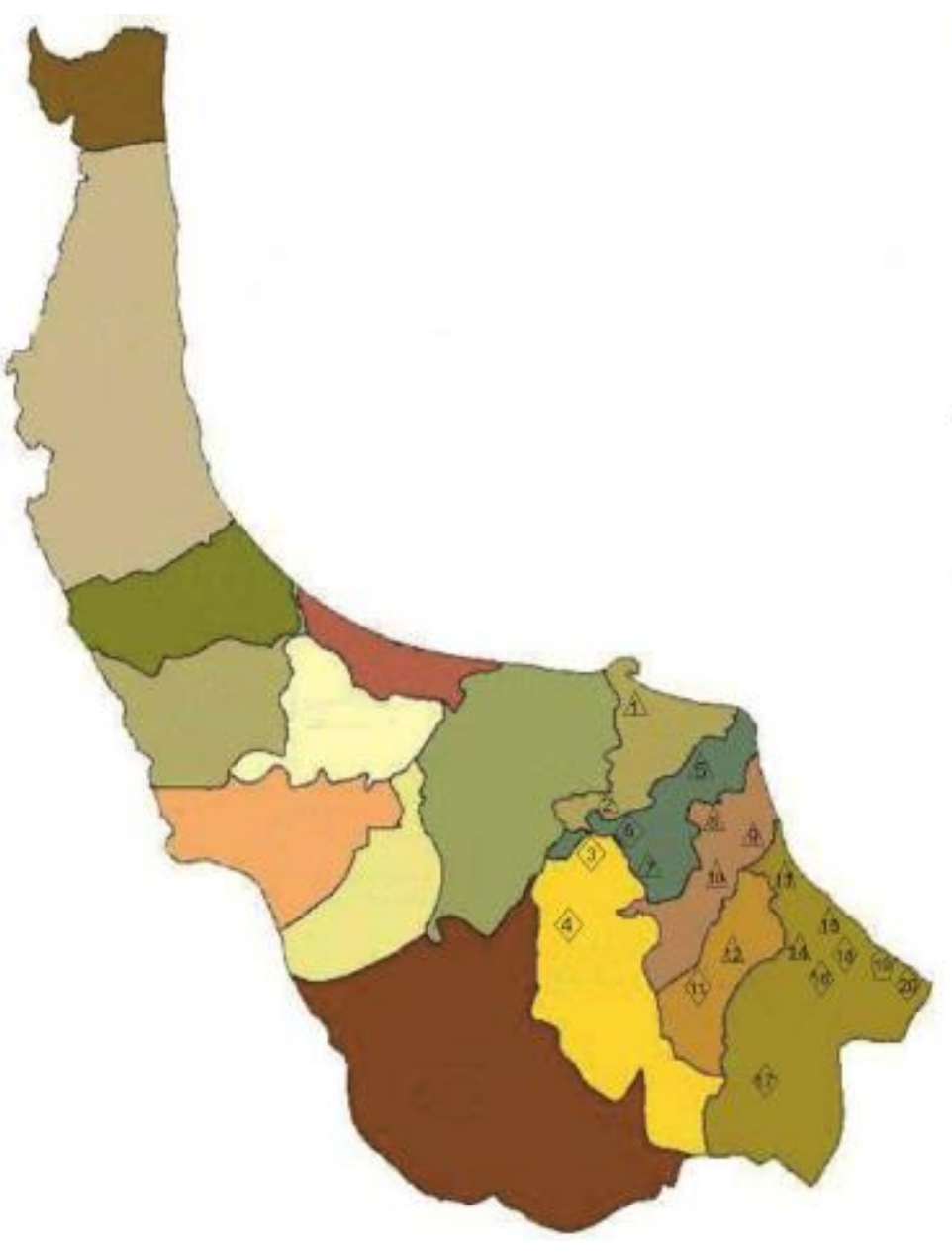

Figure 2. The atlas of

"Rain"

$\triangle$ = Phonetic difference

$\square$ = Morphological difference

$\mathrm{O}=$ syntactic difference

$\diamond=$ Lexical difference

$\bigcirc=$ Similarity to the standard Persian 
Phonetic analysis on consonants are as follows: 1.Consonant replacement;2.Consonant elision; 3.Consonant insertion.

\section{Consonant replacement:-}

Sometimes theconsonant [v] in Guilaki is the equivalent to the consonant [b] in thestandard Persian: varf

barf

"Snow"

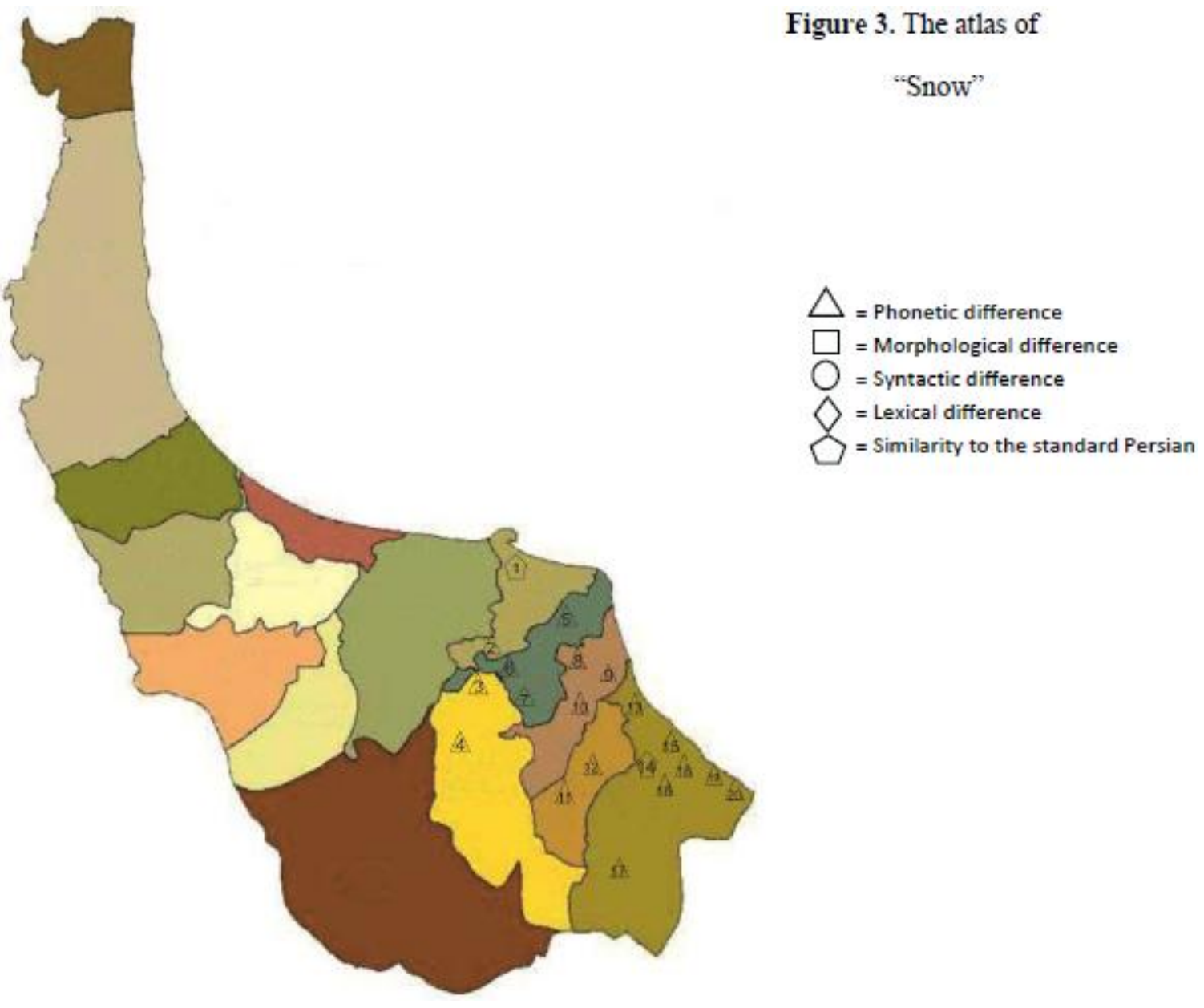




\section{Consonant elision:-}

Sometimes the consonant $[\mathrm{h}]$ in Guilaki will be deleted at the end of the word:

$\mathrm{ku}$

kuh

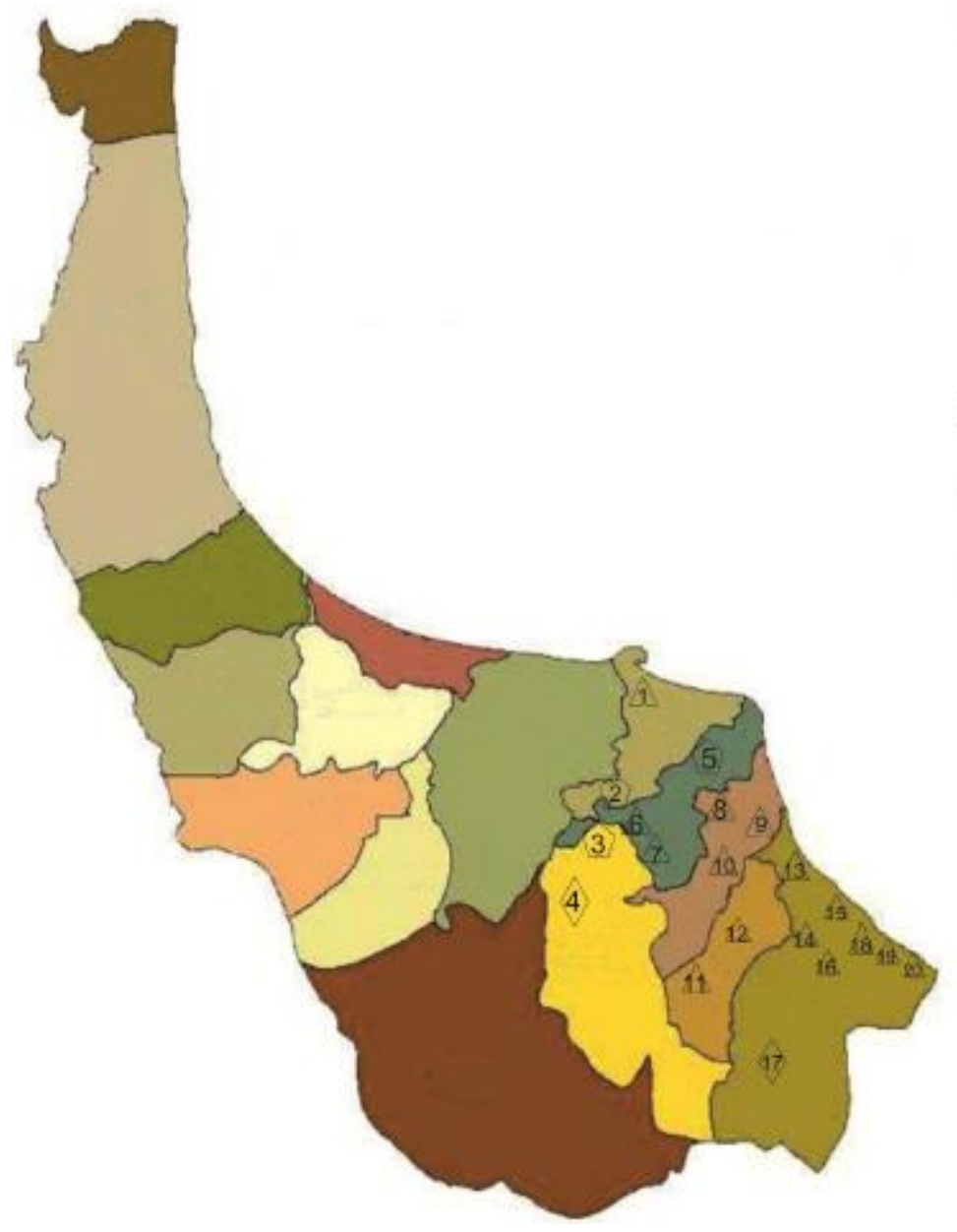

Figure 4. The atlas of

"Mountain"

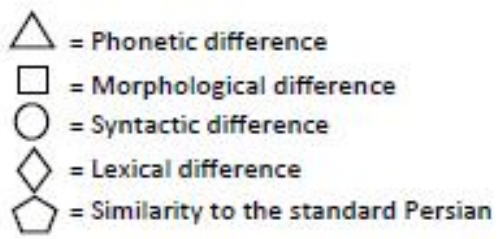


Morphological studyareasfollows: 1.The plural sign; 2.The deletion of genitive sign; 3 .The progressive sign with the intransitive verb; 4.The progressive sign with the transitive verb; 5.The independent subject pronouns; 6.The dependentsubject pronouns with the intransitive verb; 7.The dependentsubject pronounswith the transitiveverb; 8.The verbal prefix in the simple past tense with theintransitive verb; 9.The verbal prefix in the simple past tense with the transitive verb.

\section{The plural sign:-}

Sometimesthe plural suffix [an] in Guilaki is theequivalentto [hâ] in the standard Persian:

dâran

deraxthâa

"Trees"

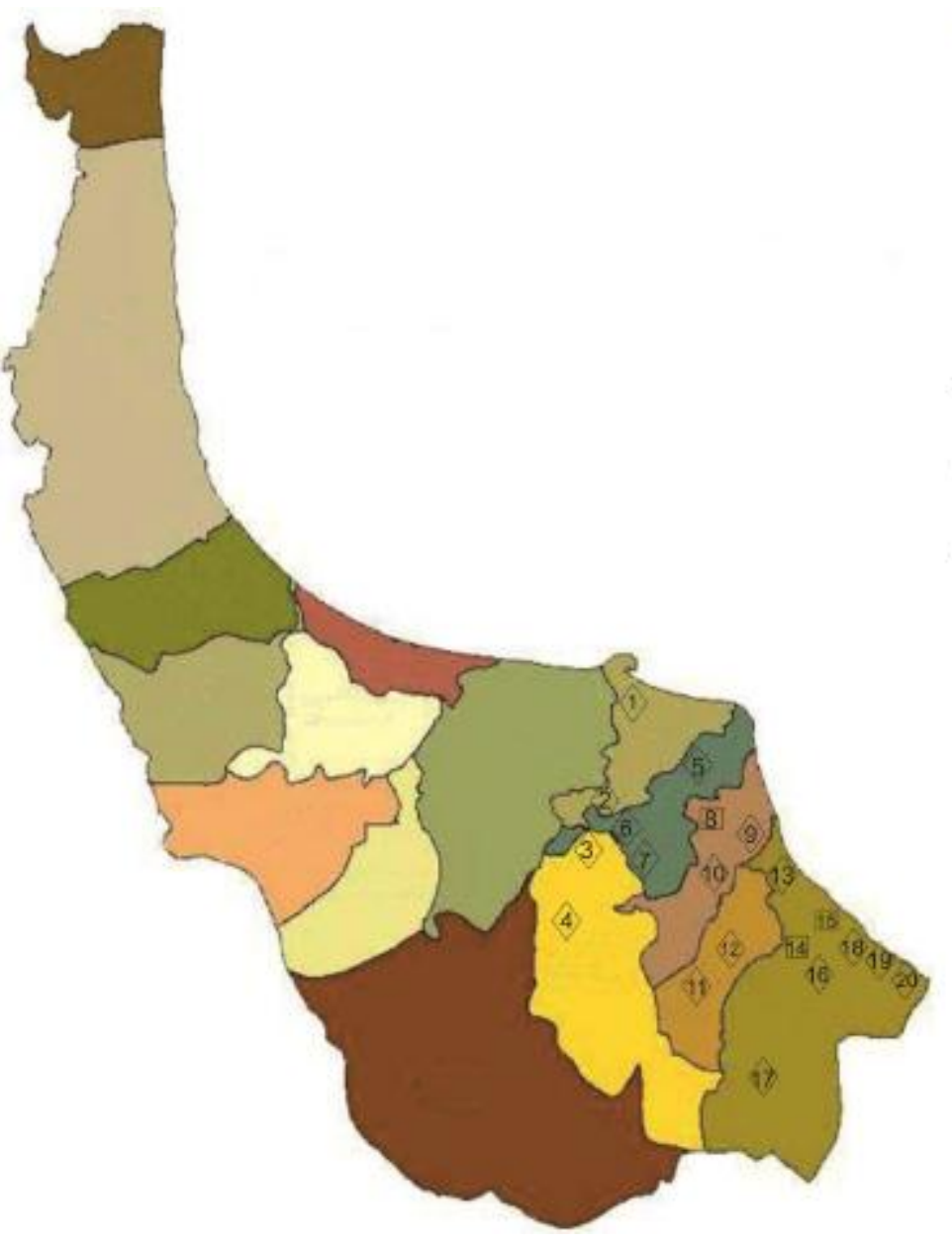

Figure 5. The atlas of

"Trees"

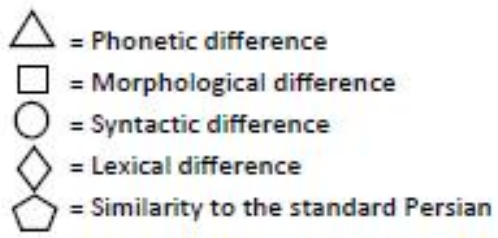


The independent subject pronouns:amo / amə / amu /âmu / mâ

mâ

"We"

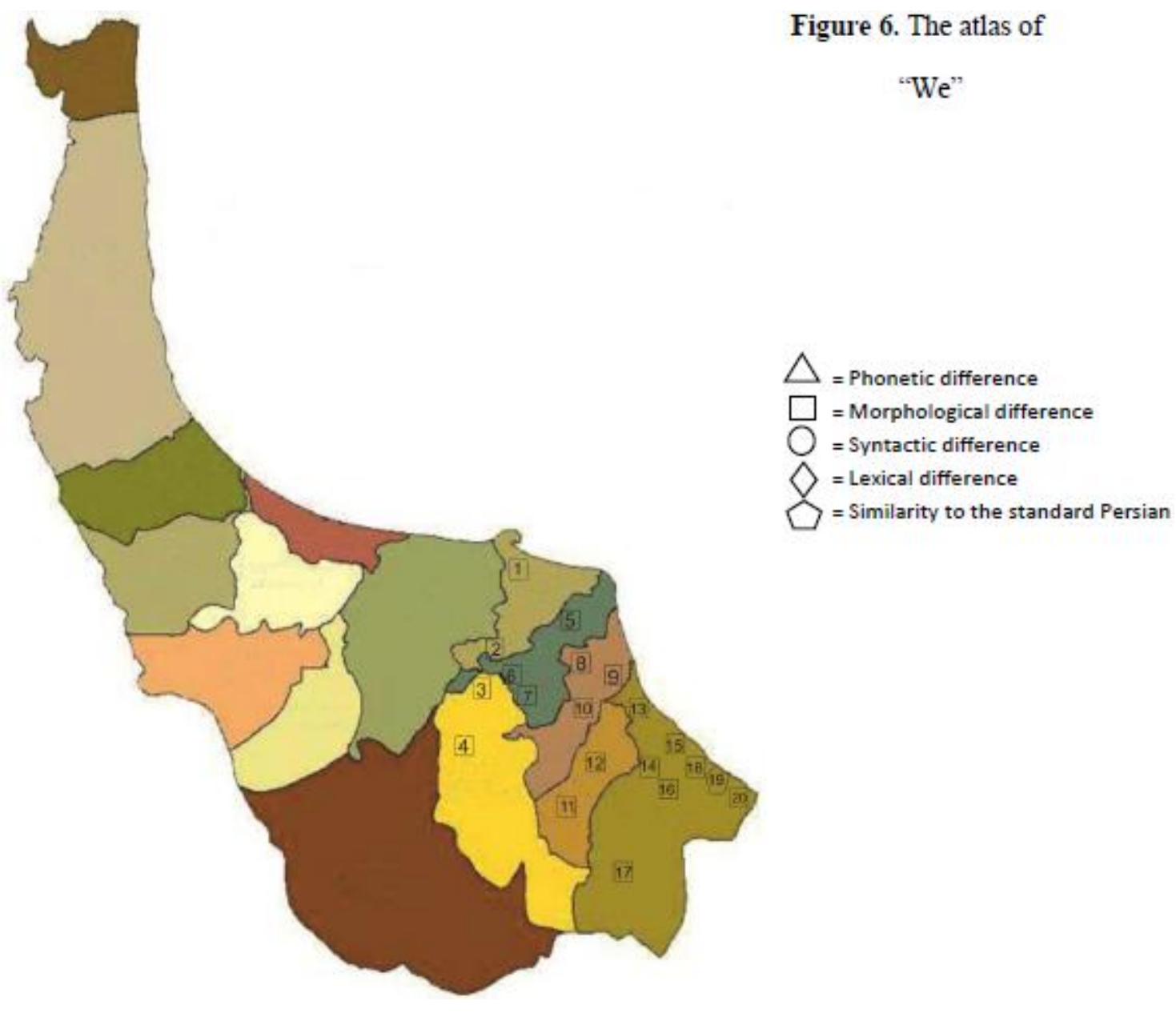


The verbal prefix in the simple past tense with the intransitive verb:baništim / beništim / bəništim

nešastim

"We sat down"

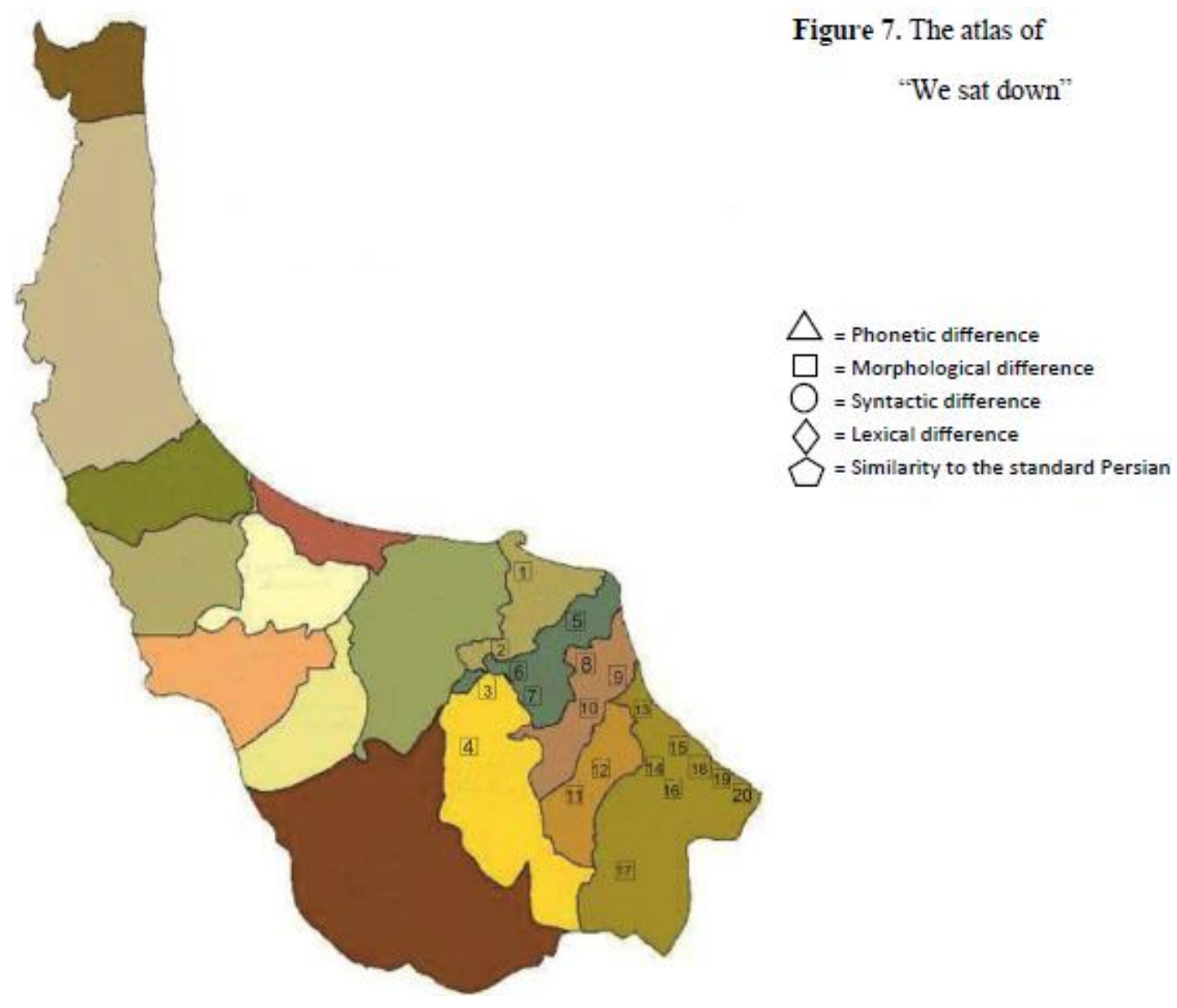


Syntacticstudy areas follows: 1.The order of the demonstrative adjective and noun; 2.The order of the number and noun; 3.The order of the adjective and noun; 4.The order of the pronoun and noun; 5.The orderof the preposition and noun; 6.The orderof the genitive and noun; 7.The indefinite sign; 8.The definite sign.

The order of the adjective and noun:-

The adjective and noun is often reversed in Guilaki and the genitive sign is $[\varnothing]$. xubmardunə

mardexub

"Good man"

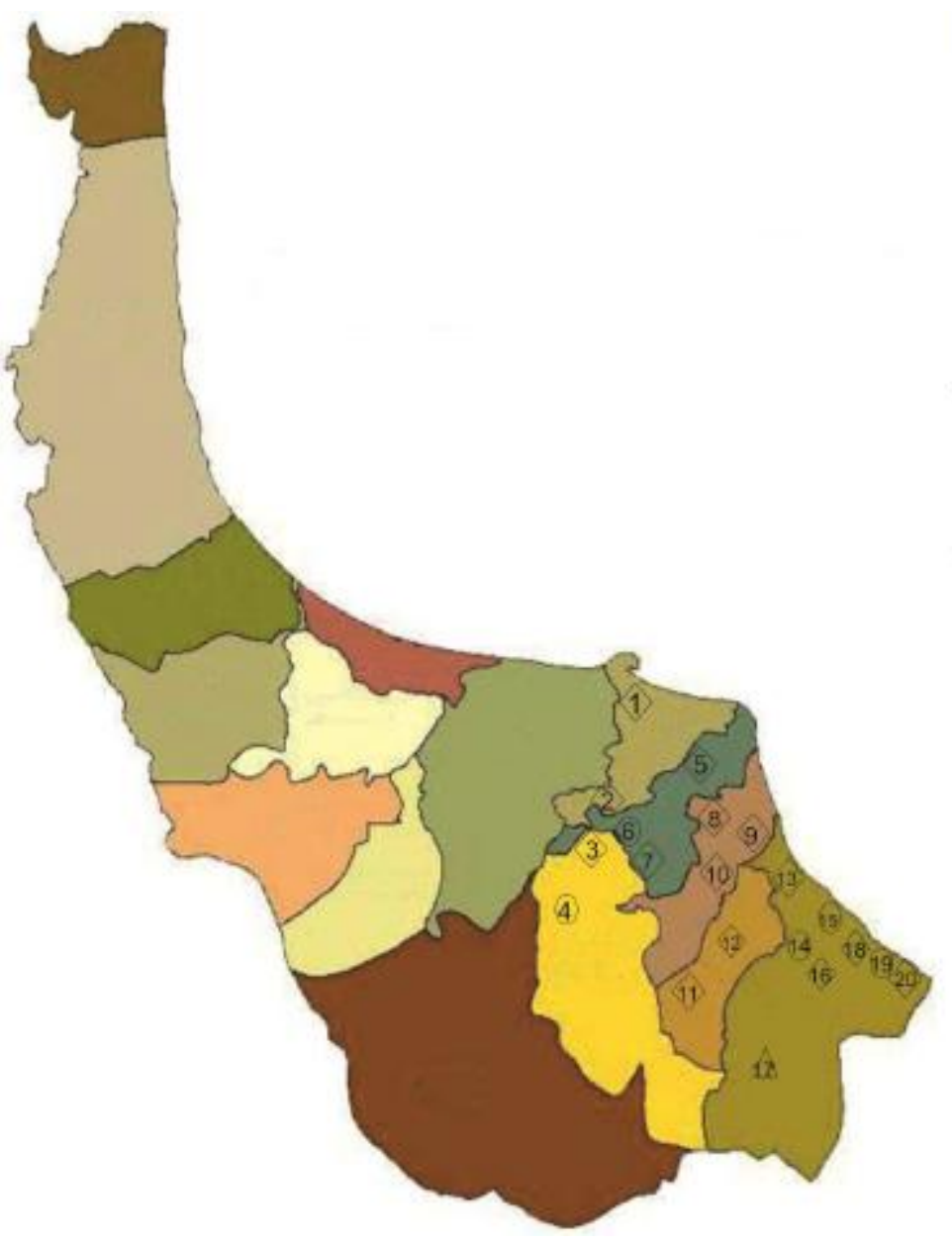

Figure 8. The atlas of

"Good man"

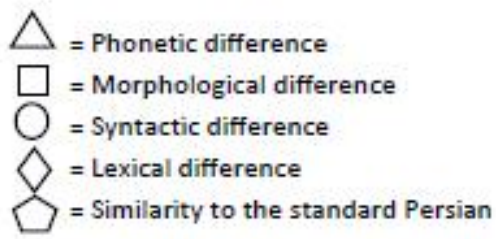


The order of the pronoun and noun:-

The pronoun comes before the nounin Guilaki and the genitive sign is [ $\varnothing]$. mima:r

mâdareman

"My mother"

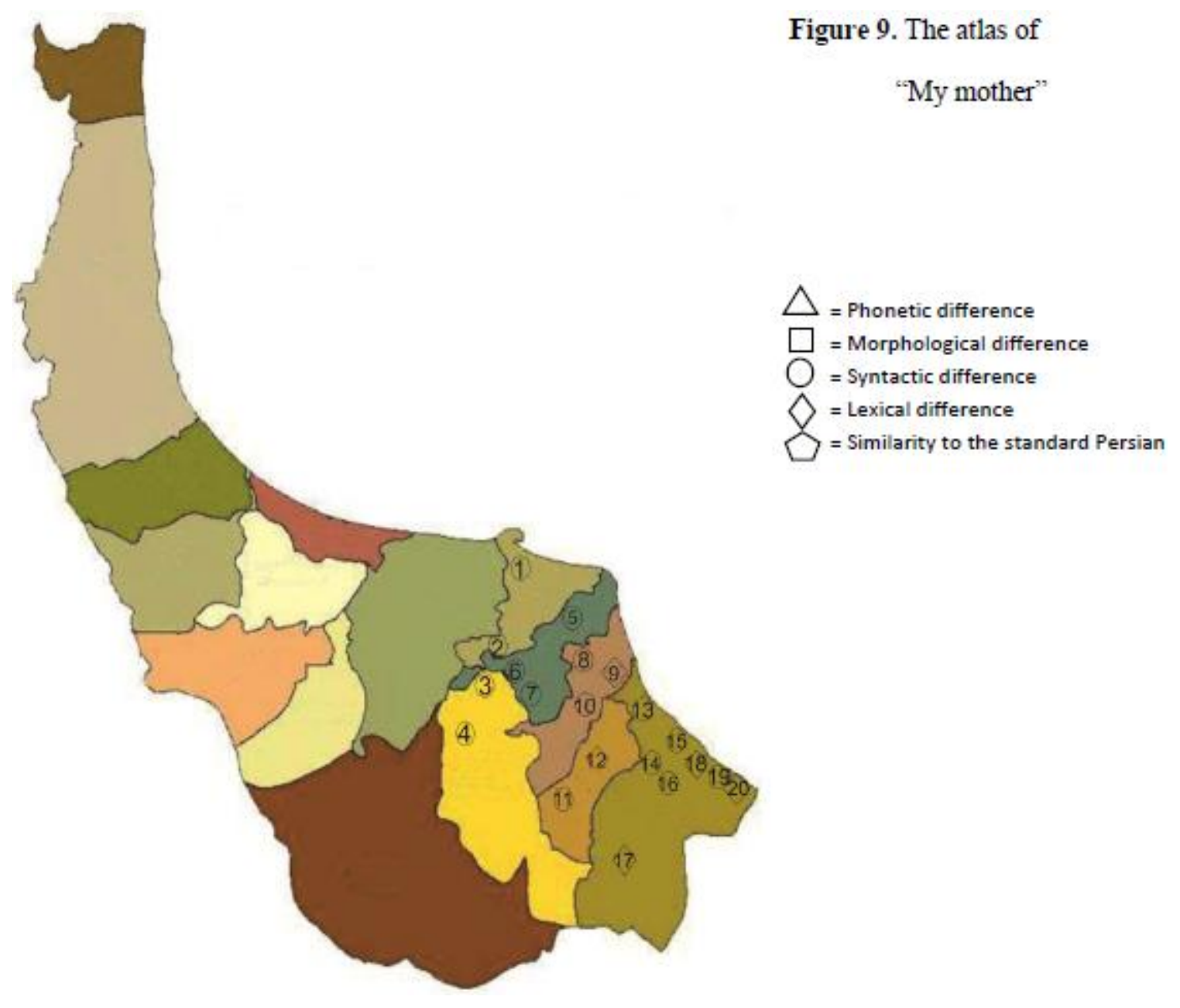


The indefinite sign:-

yektamarday/ yəktəmarday/ yemardi

yekmardi

"A man"

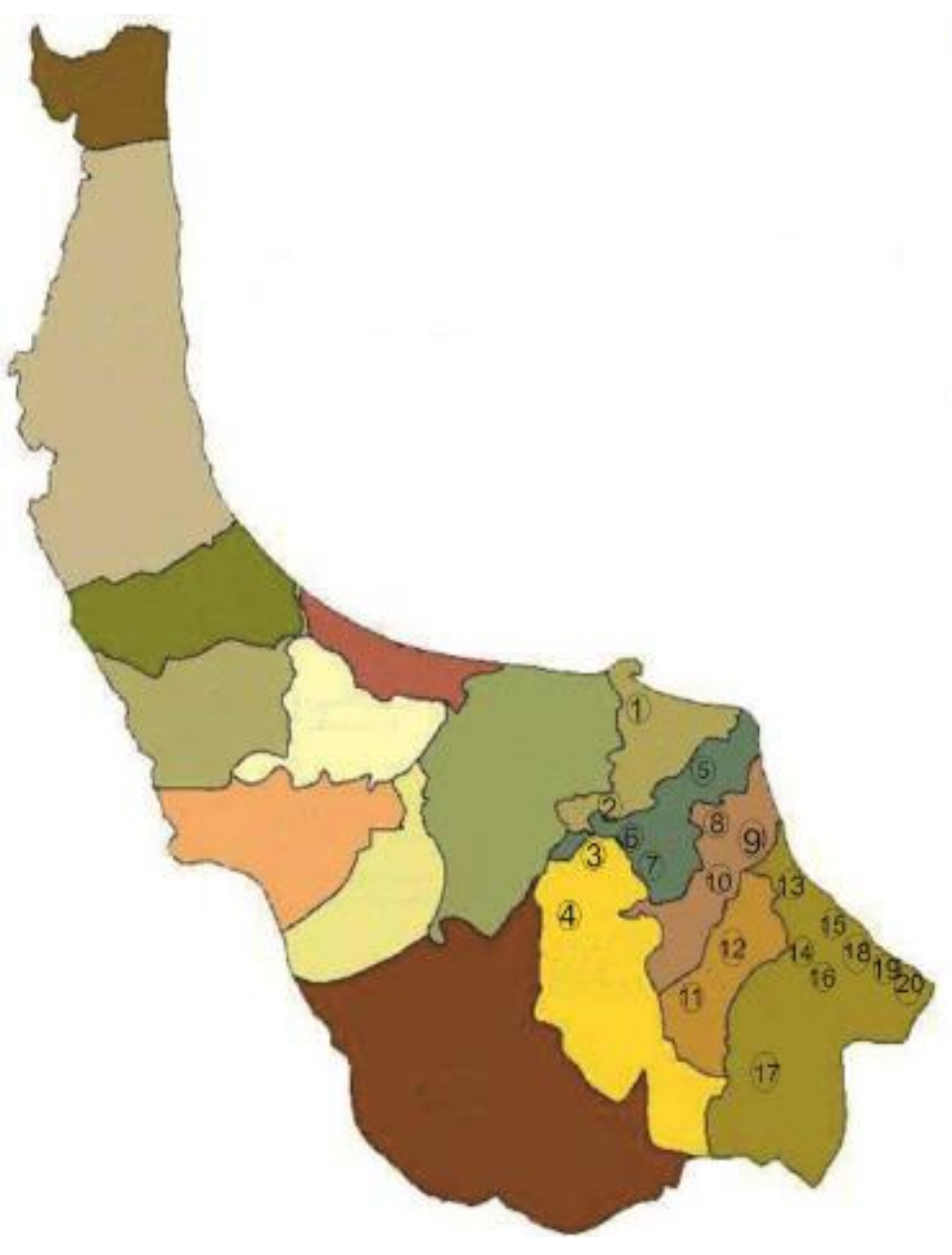

Figure 10. The atlas of

"A man"

$\triangle$ = Phonetic difference

$\square$ = Morphological difference

$\mathrm{O}=$ syntactic difference

$\searrow=$ Lexical difference

= Similarity to the standard Persian 
The definite sign:-

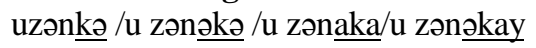

ânzan

"That woman"

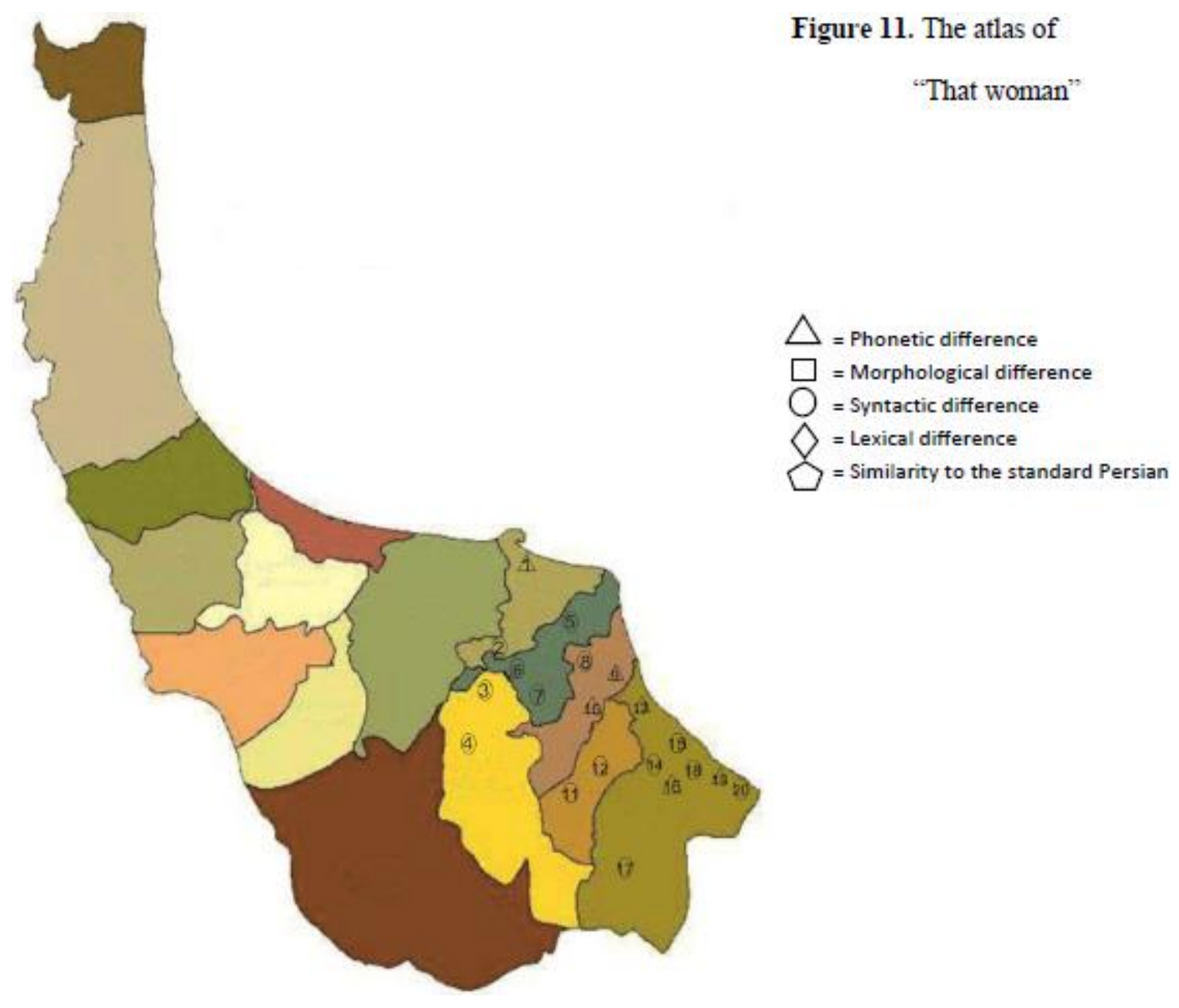


Lexical analysis:-

1. vərg/ jonəvər(g)

gorg

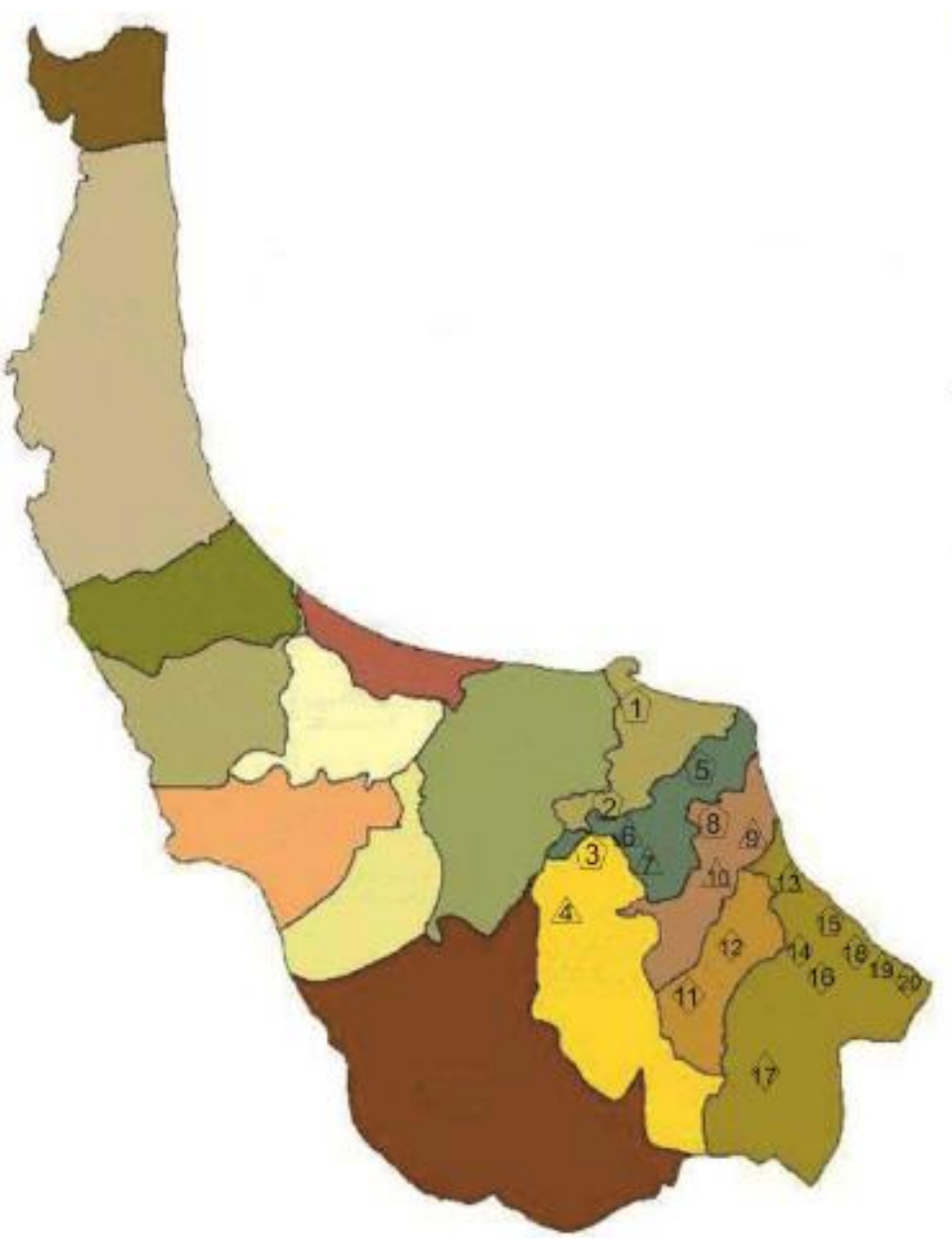

Figure 12. The atlas of

"Wolf"

$\triangle$ = Phonetic difference

$\square$ = Morphological difference

$\mathrm{O}=$ Syntactic difference

$\diamond=$ Lexical difference

$=$ Similarity to the standard Persian 
2.asəmongortak/ âsəmânkat

ra?dobarq

"Thunder and lightning"

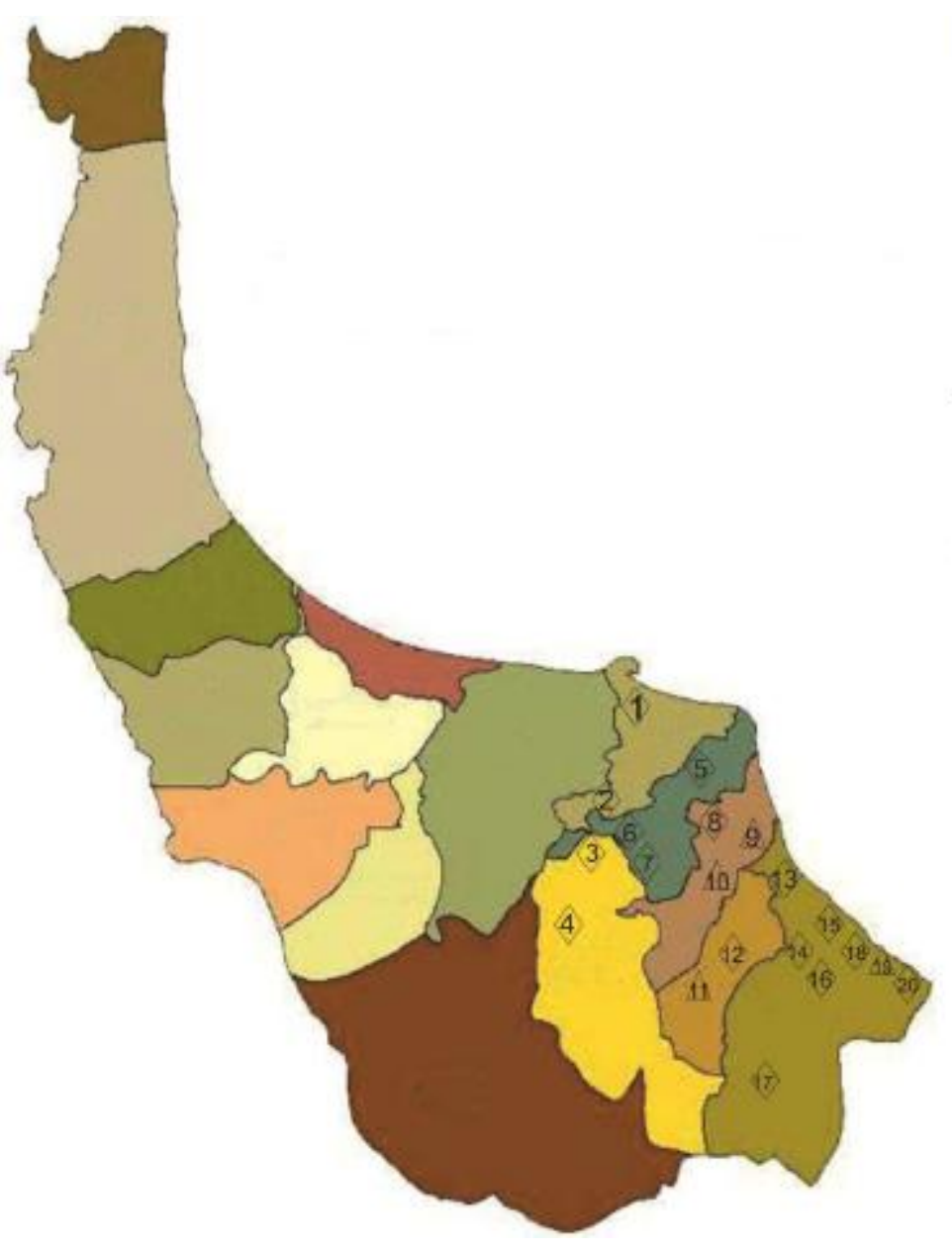

Figure 13. The atlas of

"Thunder and lightning"

$\triangle$ = Phonetic difference

$\square$ = Morphological difference

$\mathrm{O}=$ syntactic difference

$\diamond=$ Lexical difference

= Similarity to the standard Persian 


\section{Conclusion:-}

By analyzing the data in descriptive-analytic method and applying the findings with the map of the region, weidentified thephonetic, morphological,syntactic and lexicaldifferences of the language varieties in the villages of the East of Guilan compared to the standard Persian. Therefore, due to the current study, we can provide the linguistic atlas of the East of Guilan province. We can concluded that the language varieties studied in 20 villages in the East ofGuilan provinceare different accents of one dialect called Guilaki dialectwhichhave phonetic, morphological, syntactic and lexical differences with thestandard Persian.

Figure 14. The final linguistic atlas of the studied region

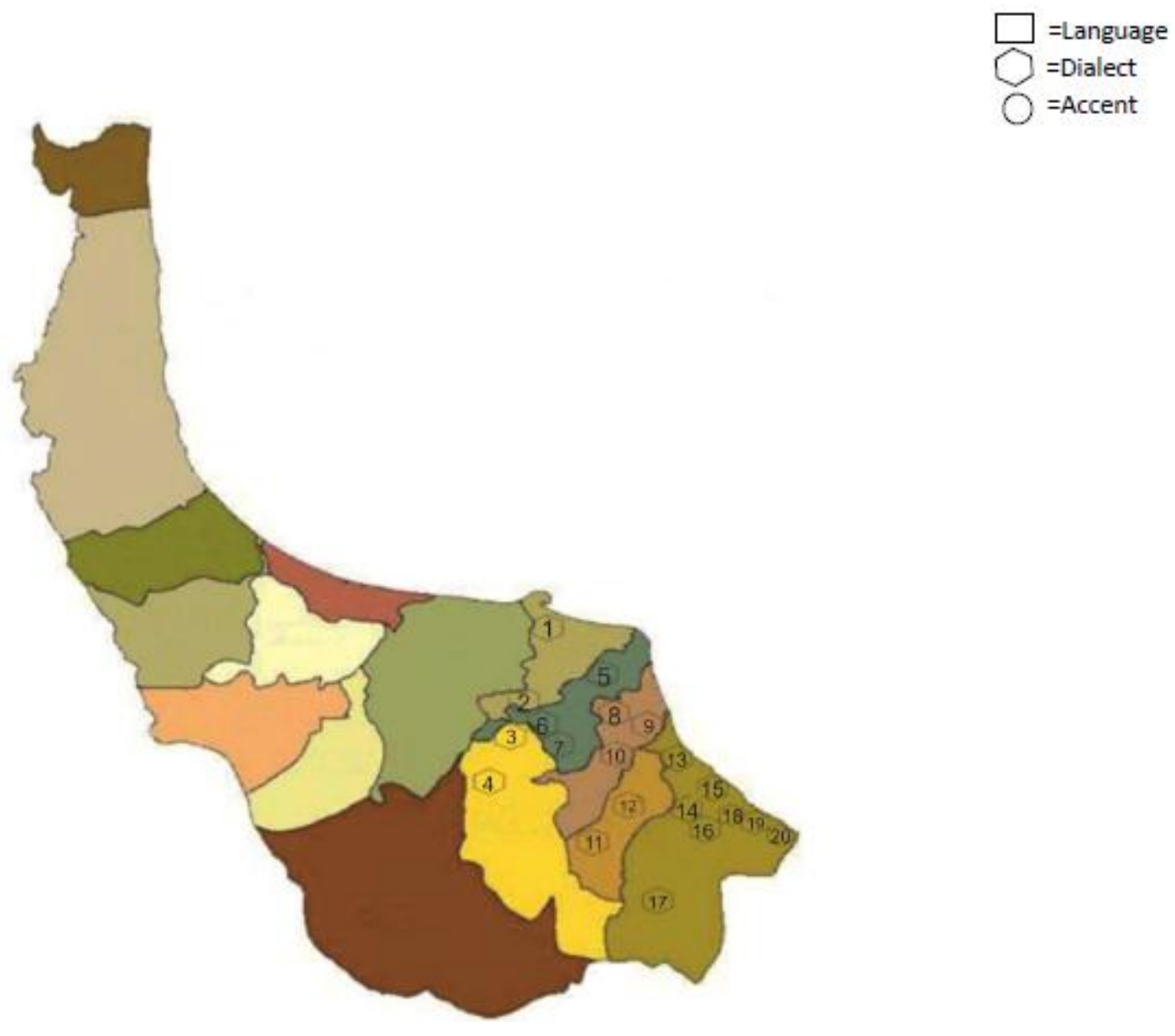

\section{Resources:-}

1. AbdollahtabarGhasemabadi, Mahdieh. 2011. "TheNational Project of the Dialectology of Iran, No.7 (30 Villages in the East of Guilan)".Master Thesis. Islamic Azad University CentralTehran Branch.

2. Abdollahzadeh, Arsalan. 2003. "The Phonetic and DialectSystem in AstanehAshrafieh". Master Thesis. Islamic Azad University Central Tehran Branch.

3. AzariHamidian, Shadi. 2003."TheNational Project ofthe Dialectology of Iran, No. 2 (40 Villages in Mazandaran and Guilan)".Master Thesis. Islamic Azad University Central Tehran Branch.

4. BakhshzadMahmoodi, Jafar. 2011. Guilaki Grammar.Rasht: GuilakanPublication.

5. Basirat, VahidandReza GholiFamian,Ali. 2011."Towards Mapping outAGuilaki DialectAtlas".Quarterly AdabPazhuhi, No. 17,Fall 2011, pp. 165-183.

6. Chodzko, Alexandre.1842.Specimens of Popular Poetry of Persia.London.

7. Christensen, Arthur. 1995.DialecteGuiläkî De Recht.Translated by Khomamizadeh. Tehran: Soroush.

8. Geiger, Wilhelm. 1896. Grundriss Der IranischenPhilologie.Strasburg. 
9. Gmelin, S.G. 1775.ReiseDurchRusslandZurUntersuchung Der DreyNaturreiche. Saint Petersburg.

10. Kalbassi, Iran. 1997.The Dialect of Kalardasht (Roudbarak).Tehran: Institute for Humanities and Cultural Studies.

11. Kalbassi, Iran. 2009.ADescriptive Dictionary of Linguistic Varieties in Iran. Tehran: Institute for Humanitiesand Cultural Studies.

12. Mir HashemiJorshari, SeyyedHannan. 2012. "The Verbal Prefix /bv-/ intheSimple Past Tense of Guilaki from Creation to Declension". Quarterly AdabPazhuhi, No. 20, Summer 2012, pp. 111-134.

13. PayandehLangaroudi, Mahmoud. 1968. A Dictionary of Guilaki and Deilami Proverbs and Idioms. Tehran: Iranian Cultural Foundation.

14. PayandehLangaroudi, Mahmoud. 1987.A Dictionary of Guilaki and Deilami. Tehran: Amir Kabir.

15. PayandehLangaroudi,Mahmoud. 1998. The Religions and Believes of Guilaki and Deilami. Tehran: Institute for Humanitiesand Cultural Studies.

16. Sartippour, Jahangir.1990.Grammatical Characteristics and A Dictionary of Guilaki Terms. Rasht: GuilakanPublication.

17. Schmit, Rüdiger. 2003.Compendium LinguarumIranicarum.Translated by Hassan RezaeeBaghbidi and others. Tehran: Ghoghnoos.

18. Shabani, Mansour.2014. "The Description and Analysis of theDiscontinuous Focusin Guilaki Language (Eshkevarat Dialect)".Quarterly AdabPazhuhi, No. 30, Winter 2014, pp. 81-99.

19. Shokouhi, Ali.1999. "The Verb Phrase Structure in the Dialect ofGuilaki in Langaroud".Master Thesis. TarbiatModarres University.

20. Sotoudeh, Manouchehr. 1953. Guilaki Dictionary. Tehran: Iranian Association. 